\title{
Effect of educational nursing guideline about paracentesis procedure care on nurses' performance
}

\author{
Eman Samir Fahmy 1, Hayah Abou Elazayiem Bayomi 2, Rokaia Fathi Mohamed 3
}

1. Clinical instructor of Medical Surgical Nursing-Faculty of Nursing - South Valley University

2. Assistant Professor of Medical Surgical Nursing - Faculty of Nursing - South Valley University

3. Lecturer of Medical Surgical Nursing - Faculty of Nursing- Minia University

Email of the corresponding author: e.sf31@yahoo.com

\begin{abstract}
Background: paracentesis is a common invasive method for managing patients with ascites; but it is associated with many potential complications. Nurses play a crucial role in preventing theses complications by providing special care before, during and after the procedures. Aim of the study: To evaluate the effect of educational nursing guideline about paracentesis procedure care on nurses' performance. Methodology: Research design: A pre/ posttest quasi-experimental research design was utilized in the present study. Sample: A convenient sample of (40) nurses was included in this study. Setting: The study was carried out at the tropical medicine departments of Qena University Hospital and Qena General Hospital, Qena governorate, Egypt. Tools of data collection: Two tools were utilized to collect data, First Tool: Structured interviewing questionnaire covered 2 parts: First part: Demographic data of the nurses. Second part included knowledge assessment sheet about paracentesis procedure. Second Tool: Observational checklist about paracentesis procedure. Study Duration: Data collection for this study was carried out through six months, from the beginning of January 2019 till the end of June 2019. Results: The study results revealed that there was a highly statistical improvement in total level of nurses' performance regarding paracentesis procedures at post and follow up phases after implementation of educational guidelines than before, with $(\mathrm{p}<0.001)$. Conclusion: The application of educational nursing guidelines about paracentesis procedure enriched nurses' knowledge and practice than before. Recommendations: Continuous nursing education about paracentesis procedure is recommended to upgrade the knowledge and skills of nurses, replication of the current study on a larger probability sample from different geographical areas to achieve generalizable results. Also it is important to investigate the effect of applying this educational nursing guideline on ascetic patients' outcome.
\end{abstract}

Key Words: Educational Nursing Guidelines- Paracentesis - Nurses Performance

\section{Introduction}

Paracentesis is a procedure in which a needle or catheter is inserted into the peritoneal cavity under sterile conditions in order to; drainage fluid from abdominal cavity in ascites condition, relieve pressure on the abdominal and chest organs, and to study chemical, bacteriological and cellular composition of the peritoneal fluid for the diagnosis of diseases.( Saberifiroozi, 2017).

However Paracentesis has been shown to be a safe and efficient method for treating patients with severe ascites that is resistant to nutritional and diuretic therapy, it can cause severe problems to the patient, and associated with some risks or complications. These complications can be divided into; systemic, local and intra-peritoneal complications. Systematic complications as (severe hypotension and infection), local as (abdominal wall hematoma and localized infection at the puncture site), and intra-peritoneal as (perforation of vessels and viscera, peritonitis) (Biecker, 2011). Several national and international studies showed that nursing adherence rate to paracentesis guideline is correlated with positive patient's outcomes, patient's safety, and reducing the risks for either local or systemic complications. (Saberifiroozi, 2017).

Hence the successful Paracentesis procedure mainly depends on skillful practitioner, highly strict aseptic technique, good preparation and carefully monitoring for the patients throughout the procedure, nurses have a major responsibilities toward patients undergoing Paracentesis because in order to minimize of intraperitoneal fluid without intravascular volume depletion, preventing injury, and inhibit infection of peritoneal cavity (Gines et al., 2014).

Nursing role toward patient undergoing paracentesis classified into pre, during and post procedure. Pre-procedure care is beginning with (assessment for patient condition, vital sings, taking consent, providing explanation about procedure, gathering needed supplies, preparing patient as emptying bladder, and positioning), while during procedure actions include (maintaining aseptic technique and closely monitoring for the patient throughout the procedure for any abnormalities) (Watkins et al., 2015). Post procedure interventions include; applying a sterile dressing and a pressure bandage at the puncture site to prevent leakage of fluid, continuing to monitor vital signs, assessing for hypovolemia, electrolyte shifts, and changes in mental status, giving prescribed albumin intravenously after large volume paracentesis and documenting the procedure (National clinical Paracentesis guidelines, 2015)

\section{Significance of the study}

The flow rate of ascetic patients (from 2016 to the end of 2017) was nearly about 250 patients in Qena university hospital (Statistical unit of Qena university hospital, 2017). Researcher viewed from working experience that there was a gap between the actual practice and expected paracentesis care according to the adopted guideline of care for ascetic patients undergoing Paracentesis.

Several conducted studies revealed that a high percent of ascetic patients undergoing paracentesis suffering from either local or systemic complication as a result of malpractice (Saberifiroozi, 2017). One of these studies is that conducted in Mansura university hospital by (EI-Sayed et al., 2018) and found that $32 \%$ of patients had signs and symptoms of hypovolemia after paracentesis because of lack of monitoring, rapid and increased drainage of ascetic fluid, as 
well as $11 \%$ suffering from peritonitis due to breaking down of aseptic technique.

Furthermore in our geographical area at Qena hospitals nurses considered that the physician is the only responsible one for performing paracentesis procedure, and there is a lack of awareness that they have a major role in assessing, preparing and monitoring patient from the beginning until finishing, as well as after the procedure. There for this study was conducted to investigate the effect of educational nursing guideline regarding paracentesis care on nurses' performance.

\section{Aim of the study}

The aim of this study was to evaluate the effect of educational nursing guideline about Paracentesis procedure care on nurses' performance

\section{Research Hypotheses}

Application of standardized nursing guideline of care about paracentesis procedure will improve nurses' performance

\section{Research Design}

A pre/post quasi-experimental research design was utilized to meet the aim of this study.

\section{Subjects}

A convenient sample of 40 nurses (25 nurses from Qena University hospital and 15 nurses from general hospital).

\section{Inclusion criteria}

All available nurses at tropical medicine department of Qena University Hospital and in the tropical department of Qena general hospital who accept to participate in the current research.

\section{Setting of the study}

The study was conducted at the tropical medicine departments in Qena University Hospital and Qena General Hospital, Qena governorate, Egypt.

\section{Study Duration}

Data collection for this study was carried out through six months, from the beginning of January 2019 till the end of June 2019.

\section{Tools of data collection}

Two tools were utilized in order to fulfill this study:

\section{First Tool:}

A structured questionnaire was designed by the researcher after reviewing of the recent related literature (James and solove, 2016, El-Sayed et al., 2018) consists of two parts:-

Part (1): Demographic data: as (name, age, marital status, place of residence, qualification, years of experience, previous training programs).

\section{Part (2): Knowledge assessment sheet}

Self-administered knowledge sheet was filled by participants nurses about abdominal paracentesis procedure include; (definition and causes of ascites, definition of paracentesis, its indications, contraindications, possible complications and how to prevent them, needed supplies, nurses role before, during and after paracentesis procedure). It consists of 20 multiple choices questions and used for nurses before and after the implementation of educational nursing guidelines through three follow up phases.

Scoring system: If nurses have score $60 \%$ and more this was considered "satisfactory" level of knowledge and if they had less than $60 \%$ it will be considered "unsatisfactory" level of knowledge.

\section{Second Tool: Observational checklist adopted from} (National Clinical Paracentesis Guideline, 2015) was used as a pre and post- test for assessing the nurses' practices pre, during and post paracentesis procedure. The steps of care categorized into (not done, incompletely done, and completely done).

\section{Scoring system}

If the nurses was done more than $70 \%$ from practices it will be considered "high performance", if they had less than $70 \%$ it will be considered "low performance".

Educational booklet was given to each nurse included in the study in order to provide educational nursing guidelines about paracentesis procedure. It is divided into two parts: Theoretical part included (definition and causes of ascites, definition of paracentesis, its indications, contraindications, possible complications and how to prevent them, needed equipment, right sites of needle insertion) and practical part included (how to prepare patients undergoing paracentesis, aseptic and right technique of needle insertion, patient's positioning, care during paracentesis and monitoring, nursing actions after finishing the procedure).

\section{Tools Validity:}

The tools were tested for content validity by a jury of five experts in the field of the study and necessary modifications were done. The tools were tested for internal consistency.

\section{Tools Reliability}

Internal consistency was evaluated using Cronbach's Alpha coefficient test which revealed that tools of the study were reliable as indicated by the value of $(0.87$ and 0.91$)$ for knowledge and practice respectively

\section{Pilot study}

A pilot study was conducted on 4 nurses $(10 \%$ of the total sample) to test clarity, completeness and to determine the time involvement. They included in our actual sample because no modifications needed to be performed.

\section{Ethical Considerations}

A written initial approval was obtained from the research ethical committee of the faculty of nursing, Minia University. The purpose of the present research was explained for every nurse and each nurse has had the right to agree or refuse participation in the study and written consent was obtained from nurses who participated in this study. They also informed that the information obtained would be confidential and would be used only for the purpose of the study. Each 
assessment sheet was coded and nurses' name didn't appear on the sheets in the purpose of anonymity and confidentiality.

\section{Data Collection Procedure}

Phase I: Preparatory and administrative phase: Administrative approval was obtained from the dean of Faculty of Nursing, Minia University to the managers of selected hospitals before implementation of the study, and then an official permission to conduct the proposed study was obtained by the researcher from the manager of Qena University Hospital and Qena General Hospital. Also the official approval for data collection was obtained from the medical consultant of the study setting after explanation of the purpose of the study. Moreover written consent was obtained from each nurse participated in this study.

Phase II: Implementation phase: Once the permission was obtained to conduct the study, the researcher initiated data collection. Collection of data was started from the beginning of January 2019 to the end of June 2019, through 4 days weekly during 2 shifts, the first shift is from ( $8 \mathrm{am}: 2 \mathrm{pm})$, and the second shift is from ( $2 \mathrm{pm}: 8 \mathrm{pm})$.

At initial interview the researcher introduced herself to initiate communication, explained the nature and purpose of the study and the nurses were persuaded by the importance of their role in providing a safe paracentesis procedure and preventing its complication. Then each nurse was involved in a pre-test, she/ he was assessed for his or her baseline knowledge using (tool I), this tool was filled individually by the nurses within about $15 \mathrm{~min}$, then each nurse was assessed individually by the researcher during her/his routine care in paracentesis procedure to determine their baseline of practice using (tool II).

Nurses were divided into groups according to shifts and time available, each group contain 2 to 7 nurses and each group of nurses selected the suitable time for receiving the teaching sessions whenever they have minimal workload. Two teaching sessions were conducted at the prepared training places for each group using the prepared teaching aids and media (booklets, power point and videos ), in order to cover the following items (definition and causes of ascites, definition of paracentesis, it's indications, contra-indications, complications, equipment, the sites of needle insertion, patient positioning, nursing role before, during, and after paracentesis procedure. Each session took around 40 minutes. Each nurse obtained a booklet that included all the training contents. The application of nursing guidelines was performed by researcher then by nurses until the researcher became sure that nurses were applying these steps perfectly. The education of the standardized nursing guidelines carried out at morning, and after noon shifts from $1 / 2 / 2019$ to $28 / 2 / 2019$.

Phase III: Evaluation phase: One month after providing of the educational intervention, the $1^{\text {st }}$ post test was conducted for evaluating the nurses' knowledge and practice; the knowledge was evaluated by allowing each nurse to refill tool (I) individually, while the practice was evaluated by the researcher through observing each nurse while performing paracentesis procedure care individually and rechecking each step if done completely, incompletely or not done through using guidelines check list tool (II). The $1^{\text {st }}$ posttest was conducted at morning, and after noon shifts from $1 / 4 / 2019$ to 30/24/2019.

One month later (from $1 / 5 / 2019$ to $31 / 5 / 2019$ ), the $2^{\text {nd }}$ posttest was done using the same technique and the last third posttest was performed by the same way after another month (from 1/6/2019 to 30/6/2019). Post-tests were conducted by interviewing and observing each participant alone.

\section{Limitations/difficulties of the study}

1. Work load of nurses was an obstacle as the researcher was waiting for a long time to start the session with participants, also this make some participants to be tired to listen and has low concentration and need continuous repetition, which required a lot of time and effort.

2. Interruptions during conducting sessions by other staff members.

\section{Statistical Analysis of Data}

Data entry was done using compatible personal computer. The statistical analysis was done using SPSS-20 statistical software package. Data were collected, revised, coded, analyzed, and tabulated using number and percentage distribution. Data were presented using descriptive statistics in the form of frequency and percentages for quantitative continuous data which were compared by using student $\mathrm{T}$-test in case of comparisons between the mean scores of the two studied groups. For multiple groups F-test or (ANOVA) was used. Person correlation analysis was used for assessment of the interrelationships between knowledge and practices pre post $\backslash$ follow up program. Statistical significance was used at $\mathrm{p}$. value $<0.05$.

\section{Results}

Table (1): Frequency distribution of the participants according to their demographic data (n=40).

\begin{tabular}{|l|c|c|}
\hline \multicolumn{1}{|c|}{ Item } & $(\mathrm{N}=40)$ & $\%$ \\
\hline Gender: & 6 & 15 \\
\hline Male & 34 & 85 \\
\hline Female & & \\
\hline Age & 21 & 52.5 \\
\hline $18-24$ & 19 & 47.5 \\
\hline$\geq 25$ & $23.22 \pm 3.91$ \\
\hline Mean+ SD & \multicolumn{2}{|c|}{} \\
\hline Years of experience & 29 & 72.5 \\
\hline 1-6yrs & 11 & 27.5 \\
\hline$\geq 7$ yrs & \multicolumn{2}{|c|}{} \\
\hline Qualification: & 5 & 12.5 \\
\hline Diploma & 32 & 80 \\
\hline Technical Institute & 3 & 7.5 \\
\hline Bachelor & \multicolumn{3}{|c}{} \\
\hline Previous courses in paracentesis
\end{tabular}




\begin{tabular}{|l|c|c|}
\hline Yes & 0 & 0 \\
\hline No & 40 & 100 \\
\hline Place of residence & & \\
\hline Rural & 25 & 62.5 \\
\hline Urban & 15 & 37.5 \\
\hline Marital status & & \\
\hline Single & 12 & 30 \\
\hline Married & 28 & 70 \\
\hline
\end{tabular}

Table (1) Illustrated frequency distribution of the participants according to their personal data. It was found that (85\%) were females; their ages ranged from 18-32 years, with a mean age of 23.22 \pm 3.91 years, more than half of them were living in rural areas, and almost of them were married. As regards the nurses' years of experience, it was noticed that (72.5\%) had less than 7 years of experience. Regarding educational qualifications of the nurses, it was found that $(80 \%)$ of them had technical institute of nursing. Concerning attendance of training courses about paracentesis and its peri procedural care, all of the studied nurses (100\%) did not attend any previous courses.

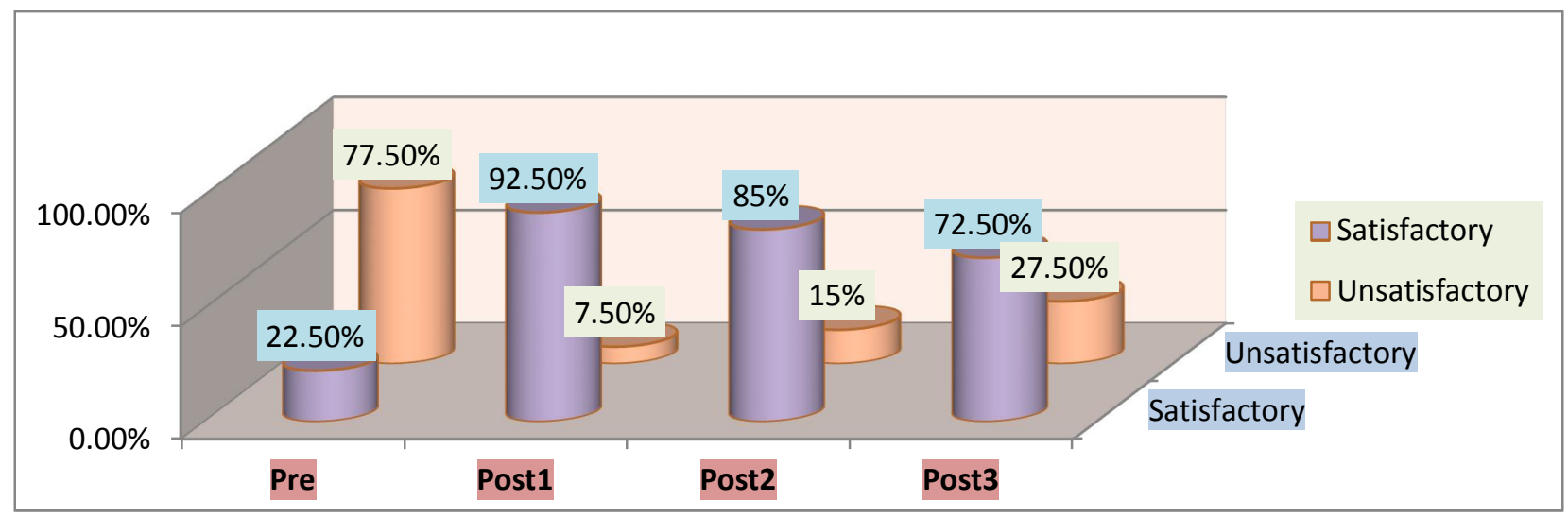

Figure (1): Comparison between total level of nurses' knowledge about paracentesis procedure at pre and post guidelines implementation $(\mathbf{n}=40)$

Figure (1): Illustrated that there was a significant improvement in nurses' knowledge regarding paracentesis procedure with a percentages of $(92.5 \%, 85 \%$, and $72.5 \%)$ at the three follow up phases after implementation of educational guidelines compared with unsatisfactory level of knowledge $(22.5 \%)$ at the pre implementation phase.

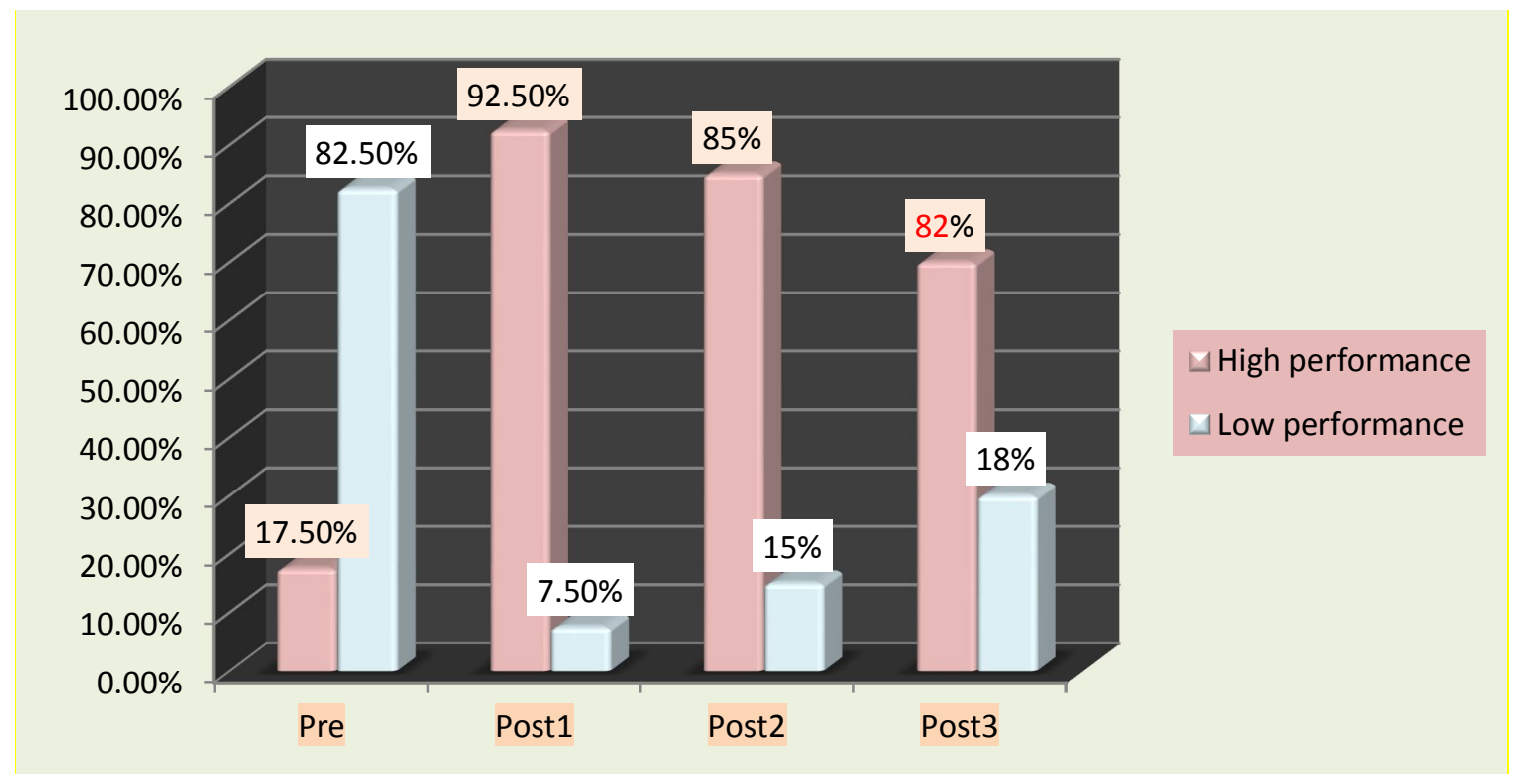

Figure (2): Comparison between total level of nurses' Practice regarding paracentesis procedure at pre and post guideline implementation $(\mathbf{n}=40)$

Figure (2): Demonstrated that there was a significant increase in total practice scores of nurses regarding paracentesis procedure after implementation of teaching guidelines at the three follow up phases represented by $(92.5 \%$, $85 \%$ and $82 \%)$ respectively when comparing with only $17.5 \%$ before implementation of teaching guidelines. 
Minia Scientific Nursing Journal (Print - ISSN 2537-012X) (Online - ISSN 2785-9797) Vol. (8) No. (1) December 2020

Table (2): Comparison between the mean scores of nurses' knowledge and practice regarding paracentesis care at pre and post the educational nursing guidelines $(n=40)$

\begin{tabular}{|c|c|c|c|c|c|c|c|c|c|}
\hline \multicolumn{4}{|c|}{ Nurses level of knowledge about paracentesis $(n=40)$} & \multirow{3}{*}{$\mathbf{P}_{1}$} & \multirow{3}{*}{$\mathbf{P}_{2}$} & \multirow{3}{*}{$\mathbf{P}_{3}$} & \multirow{3}{*}{$\mathbf{P}_{4}$} & \multirow{3}{*}{$\mathbf{P}_{5}$} & \multirow{3}{*}{$\mathbf{P}_{6}$} \\
\hline Pre & Post1 & Post2 & Post3 & & & & & & \\
\hline Mean +SD & Mean +SD & Mean +SD & Mean +SD & & & & & & \\
\hline $8.60+0.92$ & $15.35+2.04$ & $14.60+2.72$ & $13.67+3.45$ & $0.000 * *$ & $0.000 * *$ & $0.000 * *$ & $0.029 *$ & $0.002 *$ & $0.024 *$ \\
\hline \multicolumn{10}{|c|}{ Nurses level of practice regarding paracentesis procedure $(\mathrm{n}=40)$} \\
\hline Pre & Post1 & Post2 & Post3 & \multirow[t]{2}{*}{$\overline{\mathbf{P}_{1}}$} & \multirow[t]{2}{*}{$\overline{\mathbf{P}_{2}}$} & \multirow[t]{2}{*}{$\overline{\mathbf{P}_{3}}$} & \multirow[t]{2}{*}{$\mathbf{P}_{4}$} & \multirow[t]{2}{*}{$\mathbf{P}_{5}$} & \multirow[t]{2}{*}{$\mathbf{P}_{6}$} \\
\hline Mean +SD & Mean +SD & Mean +SD & Mean +SD & & & & & & \\
\hline \multicolumn{10}{|c|}{ Pre paracentesis procedure care } \\
\hline $5.60+4.43$ & $15.25+1.97$ & $14.25+273$ & $13.37+1.84$ & $0.000^{* * *}$ & $0.000 * *$ & $0.000 * *$ & 0.017* & $0.000 * *$ & $0.022 *$ \\
\hline \multicolumn{10}{|c|}{ During paracentesis procedure care } \\
\hline $4.62+4.95$ & $16.47+3.43$ & $16.32+3.02$ & $15.07+3.01$ & $0.000 * *$ & $0.000 * *$ & $0.000 * *$ & 0.772 & 0.019* & $0.005^{* *}$ \\
\hline \multicolumn{10}{|c|}{ After paracentesis procedure } \\
\hline $4.53+5.96$ & $22.02+5.08$ & $20.85+4.59$ & $18.42+1.70$ & $0.000 * *$ & $0.000 * *$ & $0.000 * *$ & 0.259 & $0.000 * *$ & 0.000 ** \\
\hline \multicolumn{10}{|c|}{ Mean score for total level of practice } \\
\hline $14.75+13.9$ & $53.80+7.85$ & $51.42+9.91$ & $48.87+5.60$ & $0.000 * *$ & $0.000 * *$ & $0.000 * *$ & 0.121 & $0.000 * *$ & $0.000 * *$ \\
\hline
\end{tabular}

NB: (P1; between pre and post1 after intervention; P2 between pre intervention and post2 intervention, P3, between pre intervention and post 3 intervention; $\mathrm{p} 4$ between post 1 intervention and post 2 intervention; $\mathrm{p} 5$ between post 1 intervention and post 3 intervention.p6 between post 2 intervention and post 3 intervention . $\mathrm{P} \leq 0.05$ is significant and **P $\leq 0.01$ is highly significant.

Table (2): Represented mean scores of nurses' knowledge and practice regarding paracentesis care at pre and post implementation of educational guideline. Regarding knowledge; it illustrated that nurses' mean scores were significantly improved through the three follow up phases compared to pretest phase, as their knowledge mean scores was (8.60 \pm 0.92$)$ at pretest and became $(15.35 \pm 2.04),(14.60 \pm 2.72)$ and $(13.67 \pm 3.45)$ at post1, post 2 and post3 respectively, with a very highly significant difference $(\mathrm{p}<0.001)$. Furthermore there was a highly significant improvement in nurses' practice after implementation of educational nursing guideline in all follow up phases compared to the pretest phase, it was (14.75 \pm 13.9$)$ at pretest phase and became $(53.80 \pm 7.85)$, $(51.42 \pm 9.91)$ and $48.87+5.60$ at post 1 , post 2 and post 3 respectively, with a very highly significant difference $(\mathrm{p}<0.001)$.

Table (3): Relation between total nurses' knowledge and practice regarding paracentesis at pre and follow up phases of guideline implementation

NB: (**P.0.01, highly significant)

\begin{tabular}{|c|c|c|c|c|}
\hline \multirow{2}{*}{ Items } & Knowledge & Practice & \multirow{2}{*}{ t test } & \multirow{2}{*}{ P value } \\
\cline { 2 - 3 } & Mean + SD & Mean + SD & & \\
\hline Pre & $\mathbf{8 . 6 0} \pm \mathbf{0 . 9 2}$ & $\mathbf{1 4 . 7 5} \pm 13.9$ & $\mathbf{2 . 9 3}$ & $\mathbf{. 0 0 6}^{* *}$ \\
\hline Post1 & $\mathbf{1 5 . 3 5} \pm \mathbf{2 . 0 4}$ & $\mathbf{5 3 . 8 0} \pm 7.85$ & 36.3 &. $\mathbf{0 0 0}^{* *}$ \\
\hline Post2 & $\mathbf{1 4 . 6 0} \pm 2.72$ & $\mathbf{5 1 . 4 2} \pm 9.91$ & 31.8 &. $\mathbf{. 0 0}^{* *}$ \\
\hline Post3 & $\mathbf{1 3 . 6 7} \pm 3.45$ & $\mathbf{4 5 . 8 7} \pm \mathbf{5 . 6 0}$ & $\mathbf{7 2 . 6 5}$ & $\mathbf{. 0 0 0}^{* *}$ \\
\hline
\end{tabular}

Table (3): It reflected that there was there were highly statistically significant improvements in nurses' practice in relation to improvement in nurses' knowledge after implementation of educational nursing guideline $(\mathrm{P} \leq 0.01)$ as compared with before.

Table (4): Relation between total level of nurses' knowledge about paracentesis procedure and their personal data at pre and post guideline implementation $(n=40)$

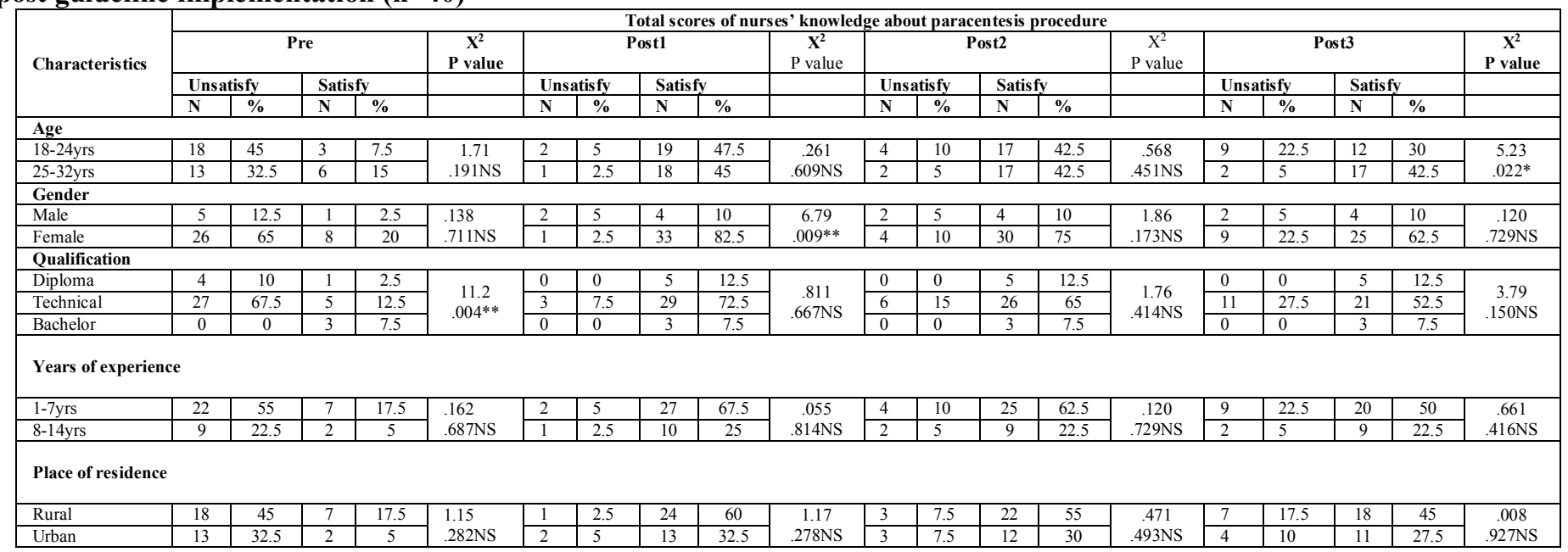


Minia Scientific Nursing Journal (Print - ISSN 2537-012X) (Online - ISSN 2785-9797) Vol. (8) No. (1) December 2020

\begin{tabular}{|c|c|c|c|c|c|c|c|c|c|c|c|c|c|c|c|c|c|c|c|c|}
\hline \multirow{4}{*}{ Characteristics } & \multicolumn{20}{|c|}{ Total scores of nurses' knowledge about paracentesis procedure } \\
\hline & \multicolumn{4}{|c|}{ Pre } & $\mathbf{X}^{2}$ & \multicolumn{4}{|c|}{ Post1 } & $\mathbf{X}^{2}$ & \multicolumn{4}{|c|}{ Post2 } & $\mathrm{X}^{2}$ & \multicolumn{4}{|c|}{ Post3 } & \multirow{3}{*}{$\begin{array}{c}X^{2} \\
\text { P value } \\
\end{array}$} \\
\hline & \multicolumn{2}{|c|}{ Unsatisfy } & \multicolumn{2}{|c|}{ Satisfy } & & \multicolumn{2}{|c|}{ Unsatisfy } & \multicolumn{2}{|c|}{ Satisfy } & & \multicolumn{2}{|c|}{ Unsatisfy } & \multicolumn{2}{|c|}{ Satisfy } & & \multicolumn{2}{|c|}{ Unsatisfy } & \multicolumn{2}{|c|}{ Satisfy } & \\
\hline & $\mathbf{N}$ & $\%$ & $\mathbf{N}$ & $\%$ & & $\mathbf{N}$ & $\%$ & $\mathbf{N}$ & $\%$ & & $\mathbf{N}$ & $\%$ & $\mathbf{N}$ & $\%$ & & $\mathbf{N}$ & $\%$ & $\mathbf{N}$ & $\%$ & \\
\hline \multicolumn{21}{|l|}{ Marital statues } \\
\hline Single & 9 & 22.5 & 3 & 7.5 & .061 & 1 & 2.5 & 11 & 27.5 & \multirow{2}{*}{$\begin{array}{c}.017 \\
.896 \mathrm{NS}\end{array}$} & 2 & 5 & 10 & 25 & \multirow{2}{*}{$\begin{array}{c}.037 \\
.847 \mathrm{NS}\end{array}$} & 3 & 7.5 & 9 & 22.5 & \multirow{2}{*}{$\begin{array}{c}.054 \\
.817 \mathrm{NS}\end{array}$} \\
\hline Married & 22 & 55 & 6 & 15 & $.804 \mathrm{NS}$ & 2 & 5 & 26 & 65 & & 4 & 10 & 24 & 60 & & 8 & 20 & 20 & 50 & \\
\hline
\end{tabular}

Table (4) Displayed that there was a significant relation between nurses' knowledge and their ages; in which nurses older than 24 years had more satisfactory level of knowledge at the third follow up phase with P value(.022*). Also, a highly significant relation was detected between nurses' knowledge and their gender; as female nurses had more satisfactory level of knowledge at post 1 phase with ( $p$ value 0.009 ). Moreover, a highly significant relation was detected between nurses' knowledge and their qualifications; in which bachelor degree nurses had more satisfactory level of knowledge at pretest phase (p 0.004). However, nurses' years of experience, residence, marital status and previous training had no influence on their knowledge score

Table (5): Relation between total level of nurses' practices about paracentesis procedure and their personal data at pre and post guidelines implementation $(n=40)$

\begin{tabular}{|c|c|c|c|c|c|c|c|c|c|c|c|c|c|c|c|c|c|c|c|c|}
\hline \multirow{4}{*}{ Characteristics } & \multicolumn{20}{|c|}{ Total score of nurses' practice regarding paracentesis procedure } \\
\hline & \multicolumn{4}{|c|}{ Pre } & \multirow{3}{*}{$\begin{array}{c}\mathbf{X}^{2} \\
\text { P value }\end{array}$} & \multicolumn{4}{|c|}{ Post1 } & \multirow{3}{*}{$\begin{array}{c}\mathbf{X}^{2} \\
\text { P value }\end{array}$} & \multicolumn{4}{|c|}{ Post2 } & \multirow{3}{*}{$\begin{array}{c}\mathbf{X}^{2} \\
\text { P value }\end{array}$} & \multicolumn{4}{|c|}{ Post3 } & \multirow{3}{*}{$\begin{array}{c}\mathbf{X}^{\mathbf{2}} \\
\text { P value }\end{array}$} \\
\hline & \multicolumn{2}{|c|}{ Low } & \multicolumn{2}{|c|}{ High } & & \multicolumn{2}{|c|}{ Low } & \multicolumn{2}{|c|}{ High } & & \multicolumn{2}{|c|}{ Low } & \multicolumn{2}{|c|}{ High } & & \multicolumn{2}{|c|}{ Low } & \multicolumn{2}{|c|}{ High } & \\
\hline & $\mathbf{N}$ & $\%$ & $\mathbf{N}$ & $\%$ & & $\mathbf{N}$ & $\%$ & $\mathbf{N}$ & $\%$ & & $\mathbf{N}$ & $\%$ & $\mathbf{N}$ & $\%$ & & $\mathbf{N}$ & $\%$ & $\mathbf{N}$ & $\%$ & \\
\hline \multicolumn{21}{|l|}{ Age } \\
\hline $18-24 \mathrm{yrs}$ & 19 & 47.5 & 2 & 5 & \multirow{2}{*}{$\begin{array}{c}1.94 \\
.163 \mathrm{NS}\end{array}$} & 1 & 2.5 & 20 & 50 & \multirow{2}{*}{$\begin{array}{c}.478 \\
.489 \mathrm{NS}\end{array}$} & 4 & 10 & 17 & 42.5 & \multirow{2}{*}{$\begin{array}{c}.568 \\
.451 \mathrm{NS} \\
\end{array}$} & 9 & 22.5 & 12 & 30 & \multirow{2}{*}{$\begin{array}{c}.3 .48 \\
.062 \mathrm{NS}\end{array}$} \\
\hline $25-32$ yrs & 14 & 35 & 5 & 12.5 & & 2 & 5 & 17 & 42.5 & & 2 & 5 & 17 & 42.5 & & 3 & 7.5 & 16 & 40 & \\
\hline \multicolumn{21}{|l|}{ Gender } \\
\hline Male & 4 & 10 & 2 & 5 & \multirow{2}{*}{$\begin{array}{c}1.22 \\
.268 \mathrm{NS}\end{array}$} & 2 & 5 & 4 & 10 & \multirow{2}{*}{$\begin{array}{c}6.79 \\
.009^{* *}\end{array}$} & 2 & 5 & 4 & 10 & \multirow{2}{*}{$\begin{array}{c}1.86 \\
.173 \mathrm{NS}\end{array}$} & 2 & 5 & 4 & 10 & \\
\hline Female & 29 & 72.5 & 5 & 12.5 & & 1 & 2.5 & 33 & 82.5 & & 4 & 10 & 30 & 75 & & 10 & 1.25 & 24 & 60 & $\begin{array}{c}.037 \\
.847 \mathrm{NS}\end{array}$ \\
\hline Qualification & & & & & & & & & & & & & & & & & & & & \\
\hline Diploma & 5 & 12.5 & 0 & 0 & & 0 & 0 & 5 & 12.5 & & 0 & 0 & 5 & 12.5 & & 0 & 0 & 5 & 12.5 & \\
\hline Technical & 27 & 67.5 & 5 & 12.5 & 6.16 & 3 & 7.5 & 29 & 72.5 & .811 & 6 & 15 & 26 & 65 & 1.76 & 12 & 30 & 20 & 50 & 4.28 \\
\hline Bachelor & 1 & 2.5 & 2 & 5 & & 0 & 0 & 3 & 7.5 & $.667 \mathrm{NS}$ & 0 & 0 & 3 & 7.5 & $.414 \mathrm{NS}$ & 0 & 0 & 3 & 7.5 & $.117 \mathrm{NS}$ \\
\hline Years of experier & & & & & & & & & & & & & & & & & & & & \\
\hline $1-7 \mathrm{yrs}$ & 24 & 60 & 5 & 12.5 & & 2 & 5 & 27 & 67.5 & & 4 & 10 & 25 & 62.5 & & 10 & 25 & 19 & 47.5 & \\
\hline $8-14 \mathrm{yrs}$ & 9 & 22.5 & $\frac{2}{2}$ & 5 & $\begin{array}{c}.005 \\
.944 \mathrm{NS}\end{array}$ & $\frac{2}{1}$ & 2.5 & 10 & 25 & $\begin{array}{c}.055 \\
.814 \mathrm{NS}\end{array}$ & $\frac{7}{2}$ & 5 & 9 & 22.5 & $\begin{array}{c}.120 \\
.729 \mathrm{NS}\end{array}$ & 2 & 5 & 9 & 22.5 & $\begin{array}{r}1.01 \\
.315 \mathrm{NS}\end{array}$ \\
\hline Place of residenc & & & & & & & & & & & & & & & & & & & & \\
\hline Rural & 19 & 47.5 & 6 & 15 & 1.95 & 2 & 5 & 23 & 57.5 & .024 & 3 & 7.5 & 22 & 55 & .471 & 8 & 20 & 17 & 42.5 & .127 \\
\hline Urban & 14 & 35 & 1 & 2.5 & $.162 \mathrm{NS}$ & 1 & 2.5 & 14 & 35 & $.877 \mathrm{NS}$ & 3 & 7.5 & 12 & 30 & $.493 \mathrm{NS}$ & 4 & 10 & 11 & 27.5 & $.722 \mathrm{NS}$ \\
\hline Marital statues & & & & & & & & & & & & & & & & & & & & \\
\hline Single & 9 & 22.5 & 3 & 7.5 & .668 & 2 & 5 & 10 & 25 & 2.07 & 2 & 5 & 10 & 25 & .037 & 4 & 10 & 8 & 20 & .091 \\
\hline Married & 24 & 60 & 4 & 10 & $.414 \mathrm{NS}$ & 1 & 2.5 & 27 & 67.5 & $.150 \mathrm{NS}$ & 4 & 10 & 24 & 60 & $.847 \mathrm{NS}$ & 8 & 20 & 20 & 50 & $.763 \mathrm{NS}$ \\
\hline
\end{tabular}

Table (5) Showed that there was a highly significant relation between nurses' practice and their gender; as female nurses had higher performance level than males at post 1 phase ( $\mathrm{p}$ 0.009). Also, nurses' qualifications had a significant relation with their practice in which bachelor degree nurses had higher performance level at pretest phase (p 0.046). However, nurses' age, years of experience, residence, marital status and previous training had no influence on their knowledge scores.

\section{Discussion}

Today, there are many challenges facing nursing staff as; an expansion in technology, consumer demand for high quality of care, pressure for cost containment, decreased a length of stay in hospitals, an aging population, and increase incidence of comorbidities. These challenges are strongly associated with a need to prepare high qualified nurses with most focus on their knowledge and practice (Duchscher, 2019).

Ascites is one of the most common pathological conditions in developing countries especially Egypt known as excessive accumulation of extracellular fluid within the peritoneal cavity, which usually develops as a result of cirrhosis of the liver. Paracentesis is the main procedure for removing ascetic fluid from the peritoneal cavity via a temporary ascetic drain. Prevention and reducing the incidence of potential paracentesis complications is a major role of nurses (Robinson, 2019). So this research was conducted to support nurses in providing safe and effective care for patients undergoing paracentesis through implementing standardized nursing guideline of care about paracentesis procedure.

\section{Discussion of the demographic characteristics of the Studied Sample}

The current study findings revealed that the majority of nurses were females; this might be due to the fact that the profession of nursing in Egypt is more specialized and private to females; because the study of nursing field was exclusive to females till only few years ago. In addition, male nurses in contrast to females prefer to travel to work abroad due to the higher salaries and better opportunities. This finding was in the same line with (Elsayed, et al., 2018) who conducted a study entitled "Applying nursing safety measure to prevent complications for liver cirrhotic patient undergoing paracentesis" at Mansoura University and found that the majority of studied nurses were females. While In contrast of (Ghonemy et al., 2016) who reported that the most of the studied sample were males and viewed that this result may reflect a social background, keeping women away from this job and due to the fact that most of female nurses are appointed to care for maternal and child health care. Also, this may be due to the fact that males cover night duties while a female does not.

As regards nurses' ages, more than half of the studied nurses were younger than 25 years, this would be due to that the young nurses constituted the main work power in the hospitals and were confined to provide the direct nursing care to patients, while the older nurses assumed the administrative 
roles. This finding was similar to that was revealed by (Mobed, et al., 2018) who conducted a study entitled "Effect of Designed Nursing Guidelines on Nursing Intervention to Reduce Complications for Cirrhotic Patients Undergoing Paracentesis" in Assuit, Egypt and found that the majority of the studied nurses were in the age group of young adults. However, this finding disagreed with (Yboa et al., 2016) who revealed that studied nurses' age ranged between 24 and 45 years.

Considering the years of experience, the majority of studied nurses had less than 7 years of experience which might be related to their young age and new graduation. This fact was consistent with (Mohamed, et al., 2018) who revealed that the majority of studied nurses had experience less than 7 years. However, against to results of (Khalil, 2013) who found that the studied nurses' experience was more than 10 years.

Regarding qualification level of the studied nurses, the present study revealed that, more than two thirds of the studied nurses had technical nursing education. This result might be due to that the technical institute of nursing provided the community with large number of nurses; due to the great turnout of students to study in nursing technical institutes; to speed up their employment and to improve their income. This finding agreed with (Elsayed, et al., 2018) whose study revealed that the majority of nurses were having technical education, while On the opposite side of (Ahmad, 2011) revealed that nursing diploma took the highest percentage in their study. Also our results revealed that no one of studied nurses had any in-service training courses related to the paracentesis procedure care; this may be attributed to their hospital focusing on courses related to infection control rather than courses related to improving the quality of nursing care. This finding was consistent with (Mobed, et al., 2018) who found that less than one third of studied nurses had in-service training courses related to paracentesis procedure, and stated that there no focus on educating and training the new staff members on techniques and protocols of nursing procedures.

Concerning marital status and place of residence, more than two thirds of studied nurses were married and resident in rural areas; this may be due to the habits of early marriage in Upper Egypt especially in the rural areas. These findings agreed with (shehab, et al., 2018) who revealed that the majority of studied nurses were married. In contrast, (Gomarverdi., et al., 2019) conducted a study in which more than half of studied nurses were single.

\section{2- Discussion of educational nursing guidelines effect on nurses' knowledge}

The results of current study highlighted the overall unsatisfactory nurses' knowledge about paracentesis procedure at the pre-implementation phase reflecting the lack in their scientific preparation. It was found that about two thirds of the nurses had inaccurate knowledge about patient's preparation, indications and contraindications of paracentesis, also the majority of them had incomplete knowledge about (needed equipments, sites of needle insertion, patient positioning, signs and symptoms of hypovolemia and peritonitis). This may be attributed in to insufficient courses related to paracentesis included in their undergraduate curriculum of nursing education, and on the other hand to lack of continuous education and in service training programs. These findings are consistent with a study conducted by (Elsayed, et al., 2018), in which nurses' knowledge was generally low before implementation of nursing safety measure to prevent complications for liver cirrhotic patient undergoing paracentesis.

After implementation of the educational guidelines, there was a significant improvement in the total scores of nurses' knowledge regarding paracentesis procedure. This fact achieved the current study hypothesis in which the application of standardized nursing guideline of care about paracentesis procedure significantly improved nurses' knowledge. This finding was in harmony with (Mobed, et al., 2018) who found a statistically significant difference in the nurses' knowledge about paracentesis items at pre and posttests. Similarly; this finding was consistent with (Venkatramana et al., 2014) who revealed that the majority of studied nurses had adequate knowledge at the post test phases. Also in consistent with the results of a study conducted by (Yboa et al., 2016), who found that the educational interventions were effective in improving the knowledge level of nursing staff and suggested that group base intervention can improve knowledge of health care workers about nursing procedures.

\section{3- Discussion of educational nursing guidelines effect on nurses' practice \\ The present study demonstrated a major deficiency in} nurses' practice before, during and after paracentesis procedure prior to implementation of the educational guideline; it was a striking finding that $(82.5 \%)$ of them had a low performance level before guidelines education, this was mainly due to that nurses were believing that they had not any role in paracentesis procedure considering it a medical procedure not as a nursing. In addition there was a lack in training programs regarding paracentesis care for new staff nurses, teaching aids and standards for care inside the units. These findings were in agreement with (Yboa et al., 2016) and (Elsayed, et al., 2018) who found low level of nurses' practice regarding care of patients undergoing paracentesis.

The implementation of the guidelines led to a significant improvement in nurses' practice in all tested areas which was observed throughout the follow up tests compared to pretest; reflected the positive impact of the guidelines education on nurses' practice and achieved the research hypothesis. This is in agreement with (Bayoumi and mahmoud, 2019) and (EImagraby and Mohammed, 2019) who found that there was a highly statistically significant improvement in nurses' practice immediately and 6 months after implementation of the educational guideline compared with before.

According to figure (1), figure (2) and table (2), the highest levels of knowledge, practice and mean scores of both were reported after implementation of the educational guideline during the follow-up (1 and 2) respectively. While, there is some decline in the level of nurses' knowledge and practice at the follow-up (3) test compared to follow-up (1 and 2 ). These results are in agreement to study done by (Jan et al., 2015) who found that the improvement in knowledge and practices was partially declined after two months of implementation of teaching protocol. These findings might be explained by the fact that the health authorities, hospital managers and head nurse of departments did not follow nurses performance and ensuring that they applying standardized guidelines of care for patients, in addition to lack of opportunity for providing continuous education in hospital to improve the nurses' performance knowledge. 


\section{4-Discussion of relation between demographic data and nurses' (knowledge/ practice) Knowledge}

The relationship between personal characteristics of nurses and their knowledge and practices was investigated in this study. It was found that there was a significant relation between nurses' knowledge scores and their ages at the third follow-up test; in which nurses older than 25 years were had more satisfactory knowledge level than the younger categories with (P. value 0.022). This result was in harmony with that of (Sabaq, et al., 2019) who found that there was a significant relation between nurses' knowledge scores and their age at the pre-program phases. On the other hand this finding is opposite to (Koshy, 2016) who found that there was no significant relation between nurses' knowledge scores and their age.

Concerning gender of nurses, the study revealed that there was a significant correlation between the gender of studied nurses and their knowledge regarding paracentesis procedure at the posttest (1), in which females had the highest percentage of knowledge than males with a $p$ value of (0.009). This finding was in the same line with (Mobed, et al., 2018) who demonstrated a significant relation between nurses' knowledge scores and their sex during the pre-test, but against the results of (Koshy et al., 2016) whose study revealed no statistical difference between knowledge score and nurses gender.

Concerning qualifications, the present study revealed that there was a highly significant correlation between the educational qualifications of studied nurses and their knowledge regarding paracentesis procedure in the pretest ( $p$ 0.004); presented as higher knowledge scores achieved by bachelor degree nurses. This finding agreed with (EImagraby and Mohammed, 2019) who illustrated that there was a significant correlation between educational qualifications and total nurses' knowledge score. This can be explained as nurses with more education response better than diploma nurses to educational training programs. However this finding is in contrast with the study of (Nimbalkar, et al., 2014) who found that the variable of educational qualifications does not play a role in nurses' knowledge.

However, no statistically significant relations were found between staff nurses' knowledge and their years of experience, place of residence, marital status and training courses. These results were against of (Thomsen et al., 2018) in which their result demonstrated a positive relationship between nurses' years of experience and attendance of previous training courses are significantly influenced their knowledge and associated with high levels of optimal competency.

\section{Practice}

Also this study investigated the relationship between improvement of nurses' practice level and their personal data through intervention phases. It was found that there was a statistically significant correlation between nurses' practice and their gender and qualification at posttest as females and bachelor degree presented higher performance level than males and other categories of education with $p$ value of $(p$ 0.009 ) and ( $p$ 0.046) respectively. These findings agreed with (Elsayed, et al., 2018) who found a significant relation between sex and educational level with practice scores. In which females nurses with a bachelor degree tended to be more adherent to hand hygiene, use of gloves, skin preparation with aseptic solution for the puncture site, closely monitoring for patient' vital signs compared with nurses with a diploma. While this finding was opposite to (Seliman, et al., 2014) who highlighted that there was no statistical significant difference in total practice scores of nurses through all assessment periods regarding their sex and educational level. However, the study revealed that nurses' age, years of experience, place of residence, marital status and training courses had no effect on their level of practice. These findings are against to the results of (Thomsen et al., 2018) and (Jan et al., 2015) who found a significant relation between nurses' practice and their age, and years of experience.

\section{Conclusion}

Based on the findings of the present study, it can be concluded that nurses who received nursing educational guidlines about paracentesis procedure showed a statistically significant improvement in their total level of knowledge and practice than before, and this is supported the research hypothesis. The improvent in nurses' performane was significantly higher after one and two months of guideline application with some decline at the third follow up phase (after three months) which indicate the need for performing training sessions for nurses at regular intervals.

\section{Recommendations}

Based on results of the present study it can be recommended that:

1. More attention must be paid to paracentesis procedure and its care in the curriculum for all educational categories of nursing students.

2. It is necessary to develop a continued nursing education and in-service training programs in internal medicine units at both Qena General and University Hospitals especially for newly jointed nurses about standardized guidelines of care ascetic patients undergoing paracentesis in order to improve the quality of care using a scientific booklet, brochures and Panners.

3. Periodic monitoring for nurses' adherence to paracentesis guidelines and to evaluate the level of nurses performance..

4. Replication of the current study on larger probability sample and on other health care settings.

\section{References:}

(1) Ahamed G.H. (2011). Effect of designed nursing protocol on nurse's knowledge and practice regarding Hemodialysis patients, submitted for partial fulfillment of Master Degree in Medical and surgical Nursing Faculty of Nursing, Assiut University. Discussion part, p.58

(2) Bayoumi, M. \& Mahmoud N., (2019). Effect of education program on nurses' knowledge and practice regarding care of central venous line in pediatric hemodialysis: evidence-based practice guidelines. Egyptian Nursing Journal, 14(2), 87

(3) Biecker E., (2011). Diagnosis and therapy of ascites in liver cirrhosis. World journal of gastroenterology. 17(10): 1237-1248

(4) Duchscher E., (2019). Understanding the concept of critical thinking. Journal of Advanced Nursing, 29(3), p 577-583.

(5) Elmagraby A., and Mohammed H., (2019). Knowledge and practice of nurses about care of ascetic patients undergoing paracentesis procedure in Sues Canal University Hospital, The Egyptian Journal of Community Medicine, Jan 2019, 31(1), p.p. 36-41.

(6) Elsayed A., Hassanin A., Mohamed H. (2018). Applying nursing safety measure to prevent complications for liver cirrhotic patient undergoing paracentesis, thesis submitted to the faculty of nursing Mansoura university in partial fulfillment of the requirements of 
master degree in Medical-Surgical nursing, Faculty of nursing, Mansoura university, Discussion part, p.77.

(7) Ghonemy T., Farag S., Soliman S., El-Okely A., \& El-Hendy Y. (2016). Epidemiology and risk factors of chronic kidney disease in the El-Sharkia Governorate, Egypt. Saudi Journal of Kidney Diseases and Transplantation, 27(1), 111.

(8) Gines P., Cárdenas A., Arroyo V., \& Rodés J., (2014): Management of cirrhosis and ascites. N Engl J Med;350:16461654

(9) Gomarverdi S., Khatiban M., Bikmoradi A., \& Soltanian A. (2019). Effects of a multi-component educational intervention on nurses' knowledge and adherence to standard precautions in intensive care units. Journal of infection prevention, 20(2), 83-90.

(10) James A., \& solove R., (2016). Paracentesis. The James, The Ohio State University Comprehensive Cancer Center.

(11) Jan Amiri M., Dehnad A., \& Haghani H. (2015). The Effect of Workshop and Multimedia Training Methods on Nurses' Knowledge and Performance on paracentesis procedure. Journal of Client-Centered Nursing Care, 4(54), 236-42.

(12) Khalil, Sh. (2013): Blood transfusion: Impact of implementing a designed nursing intervention protocol to minimize patients complications, thesis submitted for partial fulfillment of the requirements of the master degree in adult nursing, Faculty of nursing, Assiut university, Discussion part, p.76,78.

(13) Koshy P., (2016). A study to assess the knowledge and performance regarding care of ascetic patients among staff nurses in selected hospital in m.p, International Journal of Science and Research (IJSR),5(9), 2016, p.1454-1457.

(14) Mobed k., Makhlouf N., \& Abd Almageed A., (2018). "Effect of Designed Nursing Guidelines on Nursing Intervention to Reduce Complications for Cirrhotic Patients Undergoing Paracentesis". Faculty of Nursing, Assiut University, Assiut, Egypt.

(15) Mohamed, F. A., El-Bana, S. M., Mohamed, E. A. \& Abolwafa, N. F. (2018). effect of educational program on pediatric nurses' knowledge and practices regarding selected nonpharmacological techniques to relive pain in neonates, thesis submitted to the faculty of nursing minia university in partial fulfillment of the requirements of master degree in pediatric nursing, Faculty of nursing, Minia university, Discussion part, p.215.

(16) National clinical Paracentesis guidelines, (2015). Royal corwall hospitals NHS. 1-10
(17) Nimbalkar A. S., Dongara A. R., Phatak A. G., \& Nimbalkar S. M. (2014). Knowledge and attitudes regarding neonatal pain among nursing staff of pediatric department: an Indian experience. Pain Management Nursing, 15(1), 69-75.

(18) Robinson G., (2019). How to care for patients undergoing paracentesis for the drainage of ascites. Nurs Stan 2019 Oct 28. doi: $10.7748 /$ ns.2019.e11344.

(19) Sabaq A. G., El-aasar H. N., \& Mohammed M. (2019). Effect of Educational Program on Improving Nurses' Performance Regarding Arterial Blood Gases Sampling for Critically Ill Children. International journal of Nursing Didactics, 9(05), 01-10.

(20) Saberifiroozi M. (2017). Improving Quality of Care in Patients with Liver Cirrhosis. Middle East Journal of Digestive Diseases. 9 (4). 189-200

(21) Seliman A. M., Morsy W. Y., Sultan M. A., Elshamy K. F., \& Ahmed H. E. (2014). Impact of a designed head trauma nursing management protocol on critical care nurses' knowledge and practices at emergency hospital Mansoura University. Journal of American science, 10(12), 13-25.

(22) Shehab M. S., Ibrahim N. M., \& Abd-Elkader H. (2018). Impact of an Educational Program on Nurses' Knowledge and Practice Regarding Care of Traumatic Brain İnjury Patients at Intensive Care Unit at Suez Canal University Hospital. International Journal of Caring Sciences. 11(2): 1104-1116.

(23) Statistical unit of Qena university hospital, 2017.

(24) Thomsen TW, Shaffer RW, White B, and Setnik GS., (2016): effect of applying standardized guideline of paracentesis procedure on patients' outcomes. N Engl J Med; pp. 355:e21.

(25) Venkatramana C M. Labrrague L.J., Arteche D.L., \& (2014). Nurses' Knowledge and Practice of paracentesis Sterile Technique, J Nurs Care, 1(4),1:113.doi:10.4172/2167

(26) Watkins T, Whisman L and Booker P (2015). Nursing assessment of continuous vital sign surveillance to improve patient safety on the medical/surgical unit. Journal of clinical nursing. 25(1): 278281

(27) Yboa B.., Sreedharan J.; Muttappillymylil J. (2016). Knowledge about standard precautions among university hospital nurses about paracentesis care in the United Arab Emirates, Eastern Mediterranean Health Journal p.p. 331-334. 